\title{
O FECHAMENTO DAS FRONTEIRAS TERRESTRES AMAZÔNICAS E IMPACTOS NA MOBILIDADE TRANSNACIONAL ${ }^{1,2}$
}

\author{
Maria Nunes ${ }^{3}$
}

\section{INTRODUÇÃO}

Em decorrência da propagação geográfica do novo coronavírus, a maioria dos países adotou várias medidas sanitárias com o objetivo de restringir a circulação de pessoas e a propagação da doença. No subcontinente sul-americano, todos os países fecharam suas fronteiras terrestres nas semanas subsequentes à declaração da Organização Mundial da Saúde (OMS), em 11 de março de 2020, classificando a Covid-19 como pandemia.

Pactuado pela OMS que a Covid-19 tratava-se de uma emergência sanitária mundial, várias medidas de contenção da propagaçâo do vírus foram tomadas para restringir a mobilidade humana: distanciamento social, quarentenas, fechamento das fronteiras internacionais, entre outras. Entretanto, cada país adotou tais medidas acordadas aos interesses nacionais.

Isso ocorreu também com os países da região sul-americana, que adotaram medidas e estágios diferentes para questôes comuns à região. Exemplos que esclarecem essa situação são o fechamento das fronteiras terrestres, que ocorreu em diferentes períodos, e a imposiçáo de um conjunto variado de restriçóes à entrada e à circulaçáo de pessoas e bens nos respectivos territórios nacionais.

Com o fechamento das fronteiras internacionais - terrestre, fluvial e aérea -, a mobilidade transfronteiriça foi altamente impactada. Com o objetivo de limitar a entrada de estrangeiros não residentes, a medida teve grande efeito sobre a saída de imigrantes pelos corredores de passagem em pontos das fronteiras terrestres dos países amazônicos.

Este ensaio pretende resgatar, de forma incipiente, algumas consequências da falta de articulação dos países amazônicos no fechamento de suas fronteiras terrestres e na adoção das medidas de restrição da circulação e da mobilidade transfronteiriça, em função da emergência sanitária mundial instaurada.

1. DOI: http://dx.doi.org/10.38116/brua24art4

2. Este texto foi produzido no âmbito da pesquisa Fronteiras do Brasil: uma Avaliação de Política Pública, desenvolvida na Diretoria de Estudos e Políticas Regionais, Urbanas e Ambientais (Dirur) do Ipea.

3. Pesquisadora do Programa de Pesquisa para o Desenvolvimento Nacional (PNPD) na Dirur/lpea; e doutora em geografia. 
As informaçóes e os dados foram levantados principalmente por meio de matérias jornalísticas, documentos institucionais dos países fronteiriços e publicações de pesquisas acerca das temáticas fronteiriça e migratória, como MT Brasil: migraçôes transfronteiriças fortalecendo a capacidade do governo federal para gerenciar novos fluxos migratórios, desenvolvida pelo ICMPD (2016) e Migração e Refúgio no Brasil: a inserção de imigrantes, solicitantes de refúgio e refugiados no mercado de trabalho (Cavalcanti, Oliveira e Macedo, 2019), publicação do Ministério da Justiça e Segurança Pública (MJSP) - Relatório Anual 2019.5

\section{MEDIDAS DE CONTENÇÃO DA COVID-19 NAS FRONTEIRAS TERRESTRES AMAZÔNICAS}

Alguns pontos da fronteira norte brasileira se consolidaram como corredores de passagem para migração internacional. Na fronteira internacional de Roraima, via articulação fronteiriça Pacaraima/Brasil-Santa Elena do Uairén/Venezuela, registrou-se intensa entrada de imigrantes venezuelanos nos últimos anos. Após entrarem no Brasil, os venezuelanos se concentram no norte do país, formando um cinturão de ocupação nos centros urbanos de Pacaraima-Boa Vista/Roraima e Manaus/Amazonas, cujo eixo de articulação se dá via BR-174.

Por sua vez, a conurbação fronteiriça Assis Brasil-Iñapari-Bolpebra (Assis Brasil, no Acre/Brasil, Ińapari, no departamento de Madre de Dios/Peru e Bolpebra, no departamento de Pando/Bolívia) constitui o principal portal de entrada e saída das correntes migratórias haitiana e africana, cujo roteiro migratório mescla transportes aéreo e rodoviário, o qual é utilizado para alcançar a fronteira brasileira, que, em virtude da posição geográfica e da ineficiente fiscalizaçáo na fronteira peruana, possibilita a entrada de imigrantes no território brasileiro via Ińapari, município peruano fronteiriço. A partir de 2017, a migração haitiana tem desacelerado nesse ponto de fronteira, permanecendo com mais dinamismo a entrada de senegaleses, venezuelanos, angolanos, congoleses, dominicanos, entre outros.

Na fronteira internacional acreana, além de Assis Brasil, o centro urbano de Brasiléia sofre com adensamento de contingentes de pessoas migrantes que chegam em situação de vulnerabilidade, mas em razão da fiscalização mais rigorosa nas fronteiras bolivianas, a entrada de fluxos migratórios internacionais por essa conurbação - Epitaciolândia-Brasiléia/Brasil-Cobija/Bolívia, via departamento de Pando, na Bolívia - é inexistente, porém, em razão de ofertar serviços migratórios, Brasiléia recepciona pessoas em situação de mobilidade transnacional.

Atualmente, Pacaraima e Boa Vista, em Roraima, têm sofrido com a permanência desordenada e consistente de imigrantes venezuelanos em suas áreas urbanas, cujas deficiências na oferta de serviços públicos ficaram mais evidentes com a Covid-19. A relação entre a proliferação da doença e o esgotamento dos serviços de saúde pública com a entrada de venezuelanos em Roraima levou o Brasil a decidir fechar sua fronteira antes de tal medida ser tomada nas demais fronteiras da região Norte.

Em decorrência da entrada e da circulação de pessoas e mercadorias de outras regiōes do mundo, os pontos de fronteiras são sempre sensíveis no contexto de transmissibilidade de enfermidades infectocontagiosas em humanos e de sanidade animal e fitossanitária. As cidades

4. Disponível em: <https://www.justica.gov.br/sua-protecao/trafico-de-pessoas/publicacoes/anexos-pesquisas/mtbrasil_act1-3-1-4_relatorio_final.pdf>.Acesso em: 17 jun. 2020.

5. Disponível em: <https://portaldeimigracao.mj.gov.br/images/relatorio-anual/RELAT\%C3\%93RI0\%20ANUAL\%20 OBMigra\%202019.pdf>. Acesso em: 10 jul. 2020. 
acreanas fronteiriças, em decorrência da entrada de imigrantes africanos, já demonstravam preocupação com a entrada do vírus Ebola antes mesmo da pandemia da Covid-19.

Sem exceção, à época da pesquisa de campo, todos expressaram receio de que os migrantes pudessem infectar os munícipes, sendo a doença proliferada com rapidez, em razão do frágil sistema de saúde e das precárias condiçôes sanitárias e de higiene. O medo do vírus ebola chegou a instalar nas cidades acreanas o preconceito e a discriminação aos migrantes africanos (ICMPD, 2016, p. 84).

Com a pandemia da Covid-19, a preocupação com a entrada de doenças infectocontagiosas nos territórios nacionais ganhou concretude. Assim, acordados aos interesses estratégicos, os países do subcontinente começaram impondo restriçôes à entrada e à circulação em seus territórios. Porém, ao adotarem diferentes estágios e normas na implementação dos conjuntos de medidas, levaram ao impedimento de grupos de migrantes que buscavam sair pelos mesmos pontos da fronteira terrestre que haviam entrado no Brasil.

Dentro do conjunto de medidas, os países fecharam suas fronteiras internacionais como meio de restringir a entrada de passageiros em seus territórios. As restriçóes recaíram, em um primeiro momento, sobre os passageiros oriundos de países que estavam com quadros epidêmicos de contaminação pela Covid-19, e, paulatinamente, foram sendo estendidas a todos os estrangeiros (quadro 1).

QUADRO 1

Primeiras medidas e normas à entrada e mobilidade nos países fronteiriços amazônicos

\begin{tabular}{|c|c|}
\hline Países & Legislação do fechamento das fronteiras e regramento para circulação nos países amazônicos fronteiriços \\
\hline Brasil $^{1}$ & $\begin{array}{l}\text { - } 18 \text { de março: fechamento da fronteira terrestre com a Venezuela.² } \\
\text { - } 19 \text { de março: fechamento das fronteiras terrestres com Argentina, Peru, Bolívia, Colômbia, Guiana, Guiana } \\
\text { Francesa, Paraguai e Suriname. } \\
\text { - } 22 \text { de março: fechamento da fronteira terrestre com Uruguai. } \\
\text { - } 27 \text { de março: fechamento da fronteira aérea para estrangeiros. }\end{array}$ \\
\hline Bolívia $^{3}$ & $\begin{array}{l}\text { - } 14 \text { de março: suspenção temporária (14 a 31/3) de voos diretos da Europa. } \\
\text { - } 17 \text { de março: fechamento gradual de todas as fronteiras para estrangeiros. } \\
\text { - } 18 \text { de março: proibição da entrada de passageiros oriundos do espaço Schengen, Reino Unido, Irlanda, Irã, } \\
\text { China e Coreia do Sul. } \\
\text { - } 20 \text { de março: fechamento de todas as fronteiras; estabelecimento de restrição à circulação da população por } \\
\text { meio da imposição de quarentena, suspensão de transportes rodoviários públicos e interurbanos. }\end{array}$ \\
\hline Colômbia ${ }^{4}$ & $\begin{array}{l}\text { - } 15 \text { de março: restrição à entrada de estrangeiros não residentes. } \\
\text { - } 17 \text { de março: fechamento de todas as fronteiras (cidadãos nacionais e estrangeiros). }\end{array}$ \\
\hline Guiana & - 31 de março: fechamento total das fronteiras. \\
\hline Guiana Francesa & $\begin{array}{l}\text { - } 17 \text { de março: fechamento da fronteira Schengen. } \\
\text { - } 15 \text { de março: fechamento da fronteira com Suriname e Brasil. }\end{array}$ \\
\hline Peru $^{5}$ & $\begin{array}{l}\text { - } 16 \text { de março: fechamento total das fronteiras; suspenção de meios de transporte internacional de passageiros e } \\
\text { restrição à entrada de estrangeiros não residentes. }\end{array}$ \\
\hline Suriname & $\begin{array}{l}\text { - } 14 \text { de março: fechamento de fronteiras à entrada de estrangeiros. } \\
\text { - } 15 \text { de março: fechamento completo das fronteiras internacionais. }\end{array}$ \\
\hline Venezuela ${ }^{6}$ & $\begin{array}{l}\text { - } 12 \text { de março: suspenção de voos da Colômbia e da Europa e fechamento das fronteiras marítimas e terrestres. } \\
\text { - } 17 \text { de março: decreto de quarentena social. }\end{array}$ \\
\hline
\end{tabular}

Fonte: Decretos e portarias emitidas pelos países relacionados no quadro e Pêgo et al. (2020, p. 31).

Elaboração da autora.

Notas: ${ }^{1}$ Segundo as portarias que disciplinaram o fechamento das fronteiras brasileiras, as medidas consideram as notas técnicas da Agência Nacional de Vigilância Sanitária (Anvisa).

2 Portaria no 120, de 17 de março de 2020; Portaria no 125, de 19 de março de 2020; Portaria no 132, de 22 de março de 2020; Portaria № 152, de 27 de março de 2020. Disponível em: <http://www.planalto.gov.br/CCIVIL_03/Portaria/quadro_portaria.htm>. Acesso em: 10 maio 2020.

${ }^{3}$ Decreto Supremo no 4.190; Decreto Supremo № 4.192; Decreto Supremo no 4.196. Disponível em: <http://www.gacetaoficialdebolivia.gob. bo/normas/buscar_comp/(COVID-19)/page:2>. Acesso em: 5 jun. 2020.

${ }^{4}$ Decreto no 417, de 17 de março de 2020. Disponível em: <http://www.regiones.gov.co/Inicio/assets/files/51.pdf>. Acesso em: 7 jun. 2020.

5 Decreto Supremo Presidencial no 044/2020-PCM do Peru. Disponível em: <https://busquedas.elperuano.pe/normaslegales/decreto-

supremo-que-declara-estado-de-emergencia-nacional-po-decreto-supremo-n-044-2020-pcm-1864948-2/>. Acesso em: 7 jun. 2020.

${ }^{6}$ Decreto no 4.166 . 
As restriçóes impostas à mobilidade transfronteiriça (quadro 1) com o fechamento das fronteiras terrestres impactaram a rigor a entrada de estrangeiros não residentes, mas atingiram também a circulação cotidiana da população fronteiriça, criando uma série de dificuldades à dinâmica interfronteiriça.

Parte das implicações do fechamento das fronteiras terrestres dos países da região deriva da desarticulação na adoção de medidas e regras sobre as zonas fronteiriças, cujos impactos são comuns aos dois territórios nacionais. No subcontinente, entre as medidas adotadas na tentativa de deter a circulação da Covid-19 estão o fechamento total da fronteira, a suspensão de transportes terrestres de passageiros, a quarentena total, a suspensão de repatriação, e as proibiçóes à entrada de estrangeiros e de não residentes. Ocorre que essas medidas náo foram uniformizadas entre os países fronteiriços, o que deixou milhares de pessoas que se encontravam em deslocamento temporariamente "desterritorializadas", em função da demora na expedição de autorizaçôes e outros embaraços em razáo da pandemia da Covid-19, retendo vários grupos de imigrantes nas áreas adjacentes do limite internacional, impactando pequenos municípios fronteiriços.

Sob a condição de emergência sanitária, todos os países da região adotaram medidas para impedir a circulação de imigrantes pelos seus territórios (quadro 1). Entretanto, alguns empregaram medidas de controle mais rígidas, que impediram também a entrada imediata de seus cidadãos, que se encontravam fora do país quando da declaração da condição de pandemia.

$\mathrm{Na}$ fronteira brasileira, logo no início do evento pandêmico, foram registradas várias ocorrências de imigrantes dos países vizinhos sul-americanos que ficaram retidos na linha de fronteira internacional por não conseguirem permissão para entrarem seus países pátrios, e que, ao realizarem os procedimentos de saída do Brasil, não podiam mais retornar porque a fronteira encontrava-se fechada à entrada de estrangeiros não residentes. Tal medida resultou na retenção de diversos grupos de sul-americanos em vários pontos do limite internacional: no recorte sul, foram retidos argentinos e paraguaios. Já no recorte central, ficaram retidos diversos grupos de bolivianos ao longo dos primeiros meses de pandemia e, na fronteira norte, especificamente na divisa acreana, ficaram retidos grandes grupos de imigrantes de nacionalidades variadas - haitianos, paquistaneses, senegaleses e angolanos -, inclusive peruanos e bolivianos, que cumpriam o período de quarentena exigida pelos seus países em território brasileiro.

No subcontinente, o Peru e a Bolívia compuseram o rol dos países que tomaram medidas sanitárias mais severas em razão da declaração de Emergência Nacional, ${ }^{6}$ que interferiu na circulação em seus territórios: fechamento total de suas fronteiras (medida temporária) ${ }^{7}$ e restrição à circulação de veículos públicos e privados (autorizados somente veículos de atendimento à saúde). $\mathrm{O}$ conjunto de medidas desses países acabou repercutindo em pontos da fronteira brasileira, a exemplo da retenção de grandes grupos de imigrantes no município acreano de Assis Brasil, inaugurando uma crise migratória no município.

Em face da crise sanitária de Covid-19, o Acre retoma papel importante como rota internacional de imigrantes, porém em sentido contrário ao movimento migratório de

6. Decreto Supremo Presidencial no 044/2020-PCM do Peru, que declara o Estado de Emergência Nacional no país e estabelece a proibição de ingresso de estrangeiros ao Peru, porém o fechamento total das fronteiras e a proibição de circulação de veículos e transportes terrestres impediam, temporariamente, a entrada de seus nacionais.

7. Disponível em: <http://www.gacetaoficialdebolivia.gob.bo/normas/buscar_comp/(COVID-19)/page:2>. Acesso em: 10 jun. 2020. 
haitianos da primeira metade da década de 2010 e de outras nacionalidades que continuaram entrando no Brasil por esse ponto da fronteira.

No início de 2020, com a pandemia de Covid-19, essas localidades são novamente tensionadas por um movimento de saída de imigrantes oriundos do Centro-Sul do Brasil, em movimento migratório de retorno, visando alcançar outros destinos como o México e os Estados Unidos. Entretanto, com o recrudescimento das medidas de emergência sanitária no Peru, com proibição da entrada de estrangeiros e da exigência de quarentena aos seus nacionais, avolumou-se ainda mais o contingente de imigrantes retidos em Assis Brasil, ampliando a crise migratória instaurada.

Apesar de muitos peruanos permanecerem na ponte binacional sobre o rio Acre - Ponte de Integração Brasil-Peru -, em barracas improvisadas, até poderem adentrar no território peruano, muitos chegavam em situaçáo de vulnerabilidade e alguns infectados pela Covid-19, o que ampliava ainda mais os riscos de contaminação e transmissão da doença na cidade, exigindo rápida assistência das autoridades brasileiras.

Diante das medidas sanitárias adotadas pelos vizinhos para contenção da circulação de pessoas em seus territórios e para evitar o agravamento da crise já instalada nos pequenos municípios acreanos fronteiriços, em razão dos contingentes de imigrantes retidos que se avolumavam nas áreas da fronteira brasileira, o Acre, por meio do Decreto no 5.496/2020, interrompeu a circulaçáo e o ingresso de veículos públicos e privados e de transporte coletivo interestadual e internacional de passageiros em seu território, salvo os que se destinariam ao transporte de pacientes. Assim, por meio da normativa, em maio e abril, o Acre evitou a entrada de alguns grupos de peruanos ${ }^{8}$ que ficariam retidos por dias no lado brasileiro da fronteira em razão das medidas sanitárias que se encontravam vigorando no Peru, o que ampliaria ainda mais as dificuldades já enfrentadas por outros grupos de imigrantes retidos no limite internacional.

Em razão da crise migratória e da exposição desse fluxo à doença, a administração pública precisou buscar estratégias para atendimento das necessidades básicas dessas pessoas, bem como para a prevenção e o controle de transmissão da doença na regiáo. Assim, o prefeito municipal, no uso de suas atribuiçôes legais, decretou situação de calamidade pública no feito de $\mathrm{n}^{\mathrm{o}} 044$, de 31 de março de 2020, publicado no Diário Oficial do Acre, ediçáo no 12.772, de 2 de abril de 2020. Entre as condiçôes relacionadas no decreto, como agilidade na aquisição e disponibilidade de insumos e serviços para atender às necessidades dos estrangeiros com alimentação e alojamento, foram acrescidas açôes para o enfrentamento à pandemia:

atual situaçáo vivida no município de Assis Brasil, que desde a data do dia 17 de março de 2020, passou a enfrentar de forma inesperada com o isolamento de 244 (duzentos e quarenta e quatro) estrangeiros, oriundos, sobretudo, de região de alto risco do vírus em comento, que, impedidos de ingressarem no Peru, por conta do fechamento da fronteira daquele país por ordem de sua autoridade maior, e sem terem para onde ir, resolveram permanecer na circunscrição do município (Acre, 2020, p. 41).

8. Disponível em: <https://agencia.ac.gov.br/acao-coordenada-pela-seguranca-impede-entrada-de-43-peruanos-em-soloacreano/>. Acesso em: 15 jun. 2020. 
Atenta-se ao fato de que as medidas de assistência emergencial ${ }^{9}$ para acolhimento às pessoas em situação de vulnerabilidade, decorrente de fluxo migratório provocado por crise humanitária, são pactuadas na Lei nº 13.684/2018.

Informaçóes da Prefeitura de Assis Brasil davam conta de que, nos primeiros meses da pandemia, de março a setembro de 2020, a permanência de imigrantes no município era dinâmica, pois havia constantes movimentos de saída e chegada de grupos.

No final de março, o município já recepcionava quase trezentos estrangeiros que se encontravam instalados em alojamentos improvisados, os quais, segundo gestores públicos, estavam no limite da capacidade de atendimento. Desse grupo, cerca de 180 eram haitianos, paquistaneses, senegaleses e angolanos oriundos do Sul e do Sudeste do Brasil que, nas últimas semanas de março de 2020, iniciaram o longo roteiro de retorno, via conurbação fronteiriça Assis Brasil/Acre-Ińapari/Peru-Bolpebra/Bolívia.

No final de maio eram por volta de 270 imigrantes que se encontravam no município. Como no final de março, a maioria era composta por haitianos, que somavam mais de 150 . $\mathrm{O}$ volume de imigrantes que estavam no município era alterado ao longo dos meses em razáo dos grupos de peruanos que entravam no Peru, após o período de quarentena. Também havia outras nacionalidades que buscavam estratégias para atravessar a fronteira por vias e meios não convencionais, pois, ao longo da pandemia, a Rodovia Interoceânica não serviu somente ao trânsito de cargas, mas também ao fluxo migratório que buscava atravessar esse ponto da fronteira.

A dinâmica migratória de retorno permaneceu ao longo dos meses, até a reabertura da fronteira do Peru, ocorrida somente no segundo semestre de 2020. Em situação de normalidade, a crise migratória em Assis Brasil já impactaria os recursos da administração pública municipal. Segundo informações da gestão do período, até a reabertura da fronteira do Peru, o município teria gastado mais de $\mathrm{R} \$ 1$ milhão com fornecimento de serviços aos imigrantes.

Desde as primeiras semanas da declaração de emergência sanitária, grupos de sul-americanos em deslocamentos ficaram retidos no lado da fronteira brasileira. Além da fronteira acreana, vários grupos de imigrantes ficaram retidos por dias em outros pontos da fronteira internacional brasileira, aguardando o período de quarentena forçada exigido pelos países de origem para a entrada, ou autorização e trâmites migratórios. Essa situaçáo continuou ocorrendo ao longo do avanço da pandemia.

O movimento de retorno de imigrantes no subcontinente pode ter sido ampliado em virtude do cenário provável de dificuldades econômicas que os países tendem a atravessar ao longo do evento pandêmico e em pós-pandemia, em razão da diminuição das atividades econômicas, de geração de emprego e renda.

\section{CONSIDERAÇÕES FINAIS}

Com a declaração de emergência sanitária mundial, os países iniciaram a adoção de medidas e regras de circulação de pessoas e mercadorias pelos seus territórios. Dentro do conjunto de medidas para a contenção do espalhamento da Covid-19, países e blocos regionais adotaram o fechamento de suas fronteiras internacionais - aéreas, fluviais e terrestres.

9. Questões específicas da crise migratória em Assis Brasil, que por vezes exigiu a intervenção de várias instituiç̧̃̃es, entre elas o Ministério Público Federal e a Defensoria Pública da União e entidades de direitos humanos. 
No atual estágio mundial, marcado pela rapidez na circulação de bens e pessoas, o fechamento das fronteiras terrestres aparece como mais uma estratégia na contenção da circulação de doenças infectocontagiosas como a Covid-19. No subcontinente sul-americano, todos os países adotaram tal estratégia nas semanas subsequentes ao início do evento pandêmico.

Em razão da emergência de saúde, contudo, alguns vizinhos sul-americanos colocaram em execução medidas mais severas à entrada e à circulação de pessoas em seus territórios, criando dificuldades para seus próprios cidadáos adentrarem seus países, e impuseram medidas e regras diferentes sobre o mesmo recorte territorial - a linha do limite internacional -, criando dificuldades aos vizinhos.

Entre as dissonâncias na implementação das medidas, o fechamento unilateral das fronteiras terrestres ocasionou a retenção de vários grupos de imigrantes nas linhas de fronteira, criando dificuldades aos pequenos municípios fronteiriços na assistência a grandes grupos de imigrantes, por longas temporadas. Em vários pontos da linha internacional da fronteira brasileira, diversos grupos de imigrantes foram retidos desde o início da pandemia. Já em sentido contrário, na linha fronteiriça peruana com o Brasil, um grupo de venezuelanos permaneceu por vários meses aguardando a abertura da fronteira.

Para evitar todos esses prejuízos infligidos aos imigrantes (longos confinamentos na linha internacional em condiçôes desfavoráveis), os países amazônicos fronteiriços poderiam ter adotado medidas articuladas em relaçáo à migração e à mobilidade fronteiriça: focar em testagens, quarentena, isolamento e rastreamento dos doentes, e em açóes e medidas mais efetivas na repatriação de imigrantes que se encontravam em processo de deslocamento por ocasião do fechamento das fronteiras terrestres, garantindo, assim, os direitos humanos das pessoas migrantes.

\section{REFERÊNCIAS}

ACRE. Prefeitura Municipal de Assis Brasil. Decreto n⿳o 044, de 31 de março de 2020. Declara [dispóe sobre o estado de calamidade pública no município de Assis Brasil afetado por doenças infecciosas virais]. Diário do Estado do Acre, Acre, v. único, ano LIII, n. 12.772, p. 41, 2 abr. 2020 .

CAVALCANTI, L.; OLIVEIRA, T.; MACEDO, M. (Org.). Imigração e refúgio no Brasil: a inserção de imigrantes, solicitantes de refúgio e refugiados no mercado de trabalho. Brasília: OBMigra, 2019. (Relatório Anual). Disponível em: <https://portaldeimigracao.mj.gov.br/images/ relatorio-anual/RELAT\%C3\%93RIO\%20ANUAL\%20OBMigra\%202019.pdf>. Acesso em: 24 jun. 2020.

ICMPD - INTERNATIONAL CENTRE FOR MIGRATION POLICY DEVELOPMENT.

MT Brasil: migraçóes transfronteiriças - fortalecendo a capacidade do governo federal para gerenciar novos fluxos migratórios. Viena: ICMPD, 2016. Disponível em: <https://www. justica.gov.br/sua-protecao/trafico-de-pessoas/publicacoes/anexos-pesquisas/mtbrasil_act-1-31-4_relatorio_final.pdf>. Acesso em: 17 jun. 2020.

OBMIGRA - OBSERVATÓRIO DAS MIGRAÇÓES INTERNACIONAIS. Imigraçáo e refúgio no Brasil. Brasília: OBMigra, 2019. (Relatório Anual). Disponível em: <https:// portaldeimigracao.mj.gov.br/images/publicacoes-obmigra/RESUMO\%20EXECUTIVO $\% 20$ _\%202019.pdf>. Acesso em: 18 jun. 2020. 
. Acompanhamento de fluxo e empregabilidade dos imigrantes no Brasil, ano 1, n. 4, abr. 2020. (Relatório Mensal). Disponível em: <https://portaldeimigracao.mj.gov.br/images/ relatorios_mensais/2020/OBMigra_Abril_2020.pdf>. Acesso em: 23 jun. 2020.

PÊGO, B. et al. Pandemia e fronteiras brasileiras: análise da evolução da Covid-19 e proposições. Brasília: Ipea, 2020. (Nota Técnica, n. 16). Disponível em: <https://www.ipea.gov.br/portal/ images/stories/PDFs/nota_tecnica/200521_n_16_dirur.pdf>. Acesso em: 25 maio 2020. 